\title{
Initial and replacement riding surface for the orthotropic San Mateo/Hayward Bridge
}

\author{
R. Maggenti ${ }^{\mathrm{a}}$ and S. Shatnawi ${ }^{\mathrm{b}, *}$ \\ ${ }^{a}$ PECG, California Department of Transportation, Sacramento, CA, USA \\ ${ }^{\mathrm{b}}$ Shatec Engineering Consultants, LLC, El Dorado Hills, CA, USA
}

\begin{abstract}
When opened in 1967, the San Mateo/Hayward Bridge crossing the San Francisco Bay south of San Francisco incorporated the United States' first major orthotropic steel bridge deck. The mile long orthotropic steel deck of the bridge was the largest in the world at the time. The orthotropic deck is included within a 2 mile long steel high rise portion of the 7 mile long bridge. Over 40 materials were evaluated for the riding surface of the original orthotropic deck. Epoxy asphalt was chosen and remained in place well past its life expectancy until it was finally replaced in 2015 by a polyester concrete material. The paper chronicles the factors leading to the selection of the material and construction of the initial and replacement riding surface. The replacement needed to be done on a critical bridge in service connecting the East-Bay Area communities to San Francisco. This made accelerated construction a factor in choosing a replacement and motivated evaluation of polyester concrete as a possibility.
\end{abstract}

Keywords: Orthotropic bridge deck, epoxy asphalt, polyester concrete, accelerated bridge construction, overlay, riding surface, wearing surface

\section{Introduction}

The subject of this paper is the riding surface for the orthotropic portion of the San Mateo/Hayward Bridge deck. Bridge decks are arguably the most vulnerable element of a bridge to degradation, as the deck is literally where the "rubber meets the road". A deck is exposed to the greatest number of temperature swings, ultra violet light, and continuous traffic stresses. The material property objectives of a riding surface include fatigue resistance to truck wheel passages, skid resistance, protecting underlying structural capacity of the deck from deterioration, especially corrosion of steel, and the capacity to be repairable during its life cycle. These objectives are inherent in newly reinforced concrete decks, but may in time require new riding surfaces. For large steel

\footnotetext{
${ }^{*}$ Corresponding author. S. Shatnawi, Shatec Engineering Consultants, LLC, El Dorado Hills, CA, USA. E-mail: sshatnawi@shatec.net.
}

orthotropic decks a separate riding surface on the steel plates is inherently required.

Orthotropic is derived from the terms 'orthogonal' meaning having properties at 90 degree angles and 'anisotropic' meaning directionally dependent properties. An orthotropic deck plate forms the top flange of both longitudinal ribs and girders as well as transverse floor and cross beams. Thus the deck has directional properties at a 90 degree angle. Steel deck plate deformations are related to plate thickness, rib spacing, type of ribs, floor-beam spacing, overlay thickness, overlay stiffness, and bond between the steel deck and the overlay.

Orthotropic decks for major bridges were first introduced into the US in 1967 with the completion of the San Mateo/Hayward Bridge near San Francisco, California, in October, followed by the Poplar Street Bridge in St. Louis, Missouri, in November. The San Mateo/Hayward Bridge has a mile long orthotropic steel deck positioned within the 2 mile long steel 


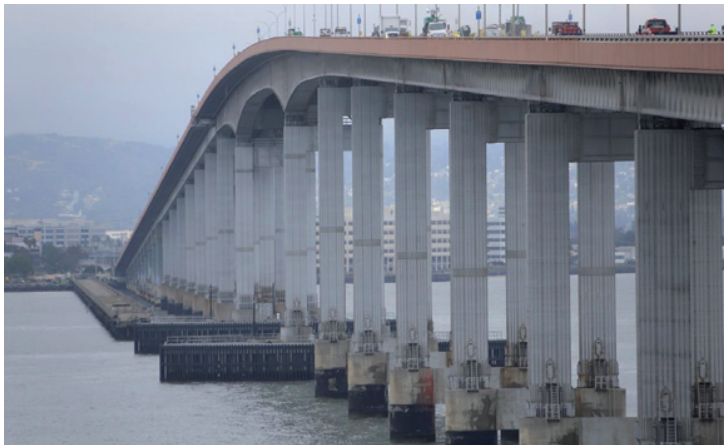

Fig. 1. San Mateo/Hayward Bridge orthotropic high rise section (Courtesy of John Huseby, Caltrans).

"high rise" portion of the 7 mile long bridge [1] (Fig. 1).

The 2 mile "high rise", designed per the 1963 American Institute of Steel Construction's Design Manual, spans $135^{\prime}$ above a navigation channel. The first and last $1 / 2$ mile of the high rise consists of steel box girders and a lightweight concrete deck. To the east of the "high rise" is a 5 mile long concrete trestle. Altogether the 7 mile long bridge is the 25th longest bridge in the world. It carries 6 lanes of traffic.

The mile long center portion of the high rise consists of 2 steel box girders, floor beams, and a steel deck stiffened with open longitudinal ribs. Welded together they form a composite structure. With the steel deck acting as the top flange for the ribs, beams and girders, the structure meets the definition of an orthotropic bridge (Fig. 2). The figure shows a photo from underneath the bridge showing a view of the deck that is welded to the ribs and a floor beam.

The orthotropic portion of the structure consists of fourteen $292^{\prime}$ spans, the main channel span of $750^{\prime}$, and the two anchor spans of $375^{\prime}$. The steel deck consists of $5 / 8^{\prime \prime}$ thick steel plate increased to $3 / 4^{\prime \prime}$ at the higher stress locations over the shipping channel. Deck sections were field bolted with splice plates requiring a riding surface thickness large enough to cover the bolt heads (Fig. 3). The figure shows workers applying the prime coat over splice plates.

The original riding surface placed in 1967 was Epoxy Asphalt Concrete (EAC), which is a thermoplastic asphalt modified with a thermosetting epoxy consisting of a mixture of epoxy resin, asphalt and resin hardeners. The 1967 choice of using EAC resulted from a thorough evaluation of over 40 materials that included laboratory tests and actual field trials on smaller orthotropic bridges [2].

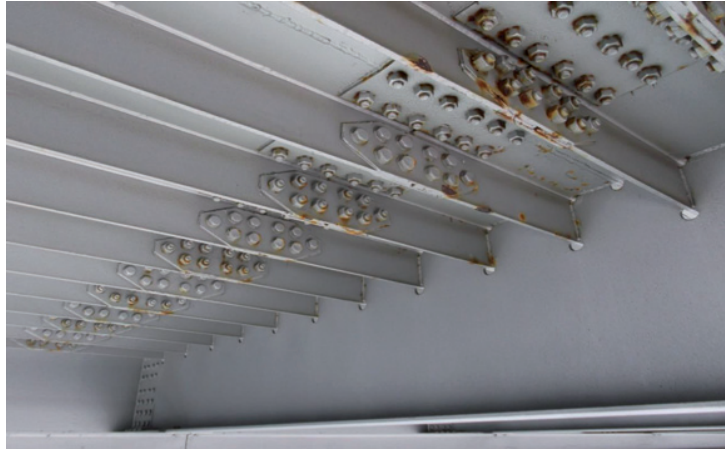

Fig. 2. Photo from underneath the bridge showing the deck plate welded to the ribs and one of the floor beams (Courtesy of Ric Maggenti, Caltrans)

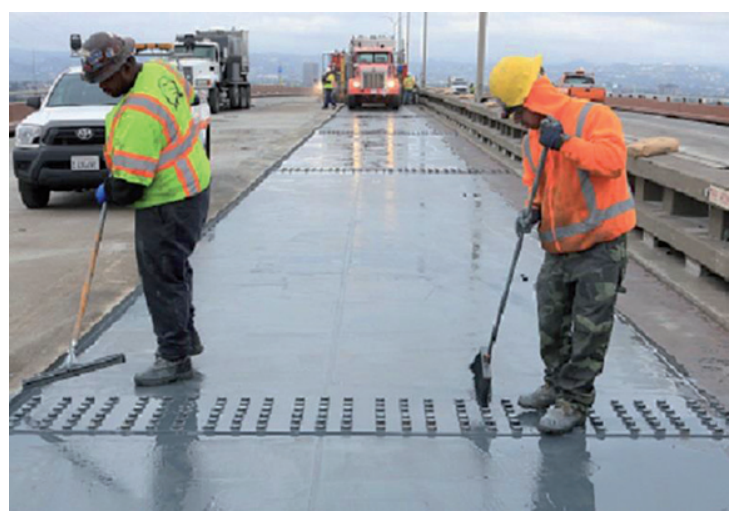

Fig. 3. Splice plate receiving prime coat (Courtesy of John Huseby, Caltrans).

Since the deck sections were field bolted with splice plates, a nominal riding surface thickness of $2^{\prime \prime}$ was needed to cover the bolt heads. Paving was done over a 3 week period. The EAC riding surface was paved in two lifts. After painting the deck with a zinc-rich paint as an added protection against corrosion, an epoxy-asphalt bond coat was applied to adhere the riding surface to the steel. The bond consisted of a mixture of epoxy resin, asphalt and resin hardeners. The EAC was paved using conventional methods and techniques used for placing a typical asphalt concrete roadway. This EAC riding surface material far exceeded expectations. It was over 30 years before any signs of decline were observed or any major maintenance was required, and was in service for almost 48 years before it was replaced in May 2015.

When time came for the replacement of the original deck surface, substantial consideration had to be given to EAC performance on this bridge, 
as well as on other bridges, airfield pavements, and roadways. Indeed, EAC was the riding surface placed in 2013 on the signature structure of the east spans replacement of the San Francisco/Oakland Bay Bridge (SFOBB) where approximately 5,000 tons of EAC were placed on 360,000 square feet of steel on the Self-Anchored-Suspension (SAS) portion of the bridge. The signature structure for the 2.2 mile-long SFOBB new east spans is the 2,000' long billion dollar SAS steel orthotropic box girder bridge sandwiched between the concrete box girder structures.

The replacement riding surface for the San Mateo/Hayward Bridge deck, however, was to be on a bridge in service. This was a considerable factor to take into account. Weighing all factors, a polyester concrete using a zinc rich prime coat placed directly on the steel deck was the material of choice.

\section{Riding surface of an orthotropic bridge}

Steel bridge deck surfaces have a long history dating back to before 1930. Many of these early steel decks were bare having tire traffic directly on the steel. Although patterns were often machined into the surface, skid resistance, was still an issue. By the 1930s the "battledeck floor" steel bridge deck was being used as a measure to reduce dead weight of bridges. The "battledeck" consisted of steel flat plate supported by I-beam stringers typically spaced between $1^{\prime}$ and $3^{\prime}$. Opened in 1936, the $310^{\prime}$ span Harlem River Lift Bridge and the 350' span Bronx Kill Bridge in New York City incorporated a "battledeck" system. To accommodate a riding surface on the steel, $3 / 4^{\prime \prime}$ thick by $3 / 8^{\prime \prime}$ wide steel strips were tack welded to the deck surface to form a $10^{\prime} \times 22^{\prime}$ grid pattern. The steel deck surface was red lead painted followed by a coat of asphaltic cement. Pre-fabricated pavers formed the riding surface. The $1^{\prime \prime}$ thick pavers were $1^{\prime}$ wide $\times 2^{\prime}$ long. These were made up of " $\mathrm{min}$ eral filler" and fibers held together by an asphalt binder. An aggregate chip pressed into the surface provided friction [3]. This was labor intensive with extensive hand work. The riding surface performed adequately as did other labor intensive with extensive hand work systems on larger steel deck bridges in Europe. However when the first major orthotropic bridges were planned for the USA and Canada in the early 1960s, a more mechanized solution was sought [2]. Eventually, the riding surface was also to add structural integrity to the bridge.
The primary function of any riding surface of a bridge deck is, of course, to provide for a smooth riding quality and adequate skid resistance. For an orthotropic deck it is also desirable to provide for composite action with the superstructure. An effective bond between the steel and the overlay increases the stiffness by providing composite action, thus lowering fatigue stresses in the steel deck, particularly at the welds attaching the ribs or stiffeners to the deck. As per AASHTO Bridge Design Specifications 2012: "the wearing surface should be regarded as an integral part of the total orthotropic deck system and shall be specified to be bonded to the top of the deck plate...the wearing surface shall be assumed to be composite with the deck plate, regardless of whether or not the deck plate is designed on that basis...". Protecting the steel deck from corrosion is still another objective. Other properties are durability and the ability to be repaired throughout its life cycle. Durability properties include resistance to cracking, resistance to load associated stresses due to repetitive traffic loading, resistance to environmental stresses such as sunshine ultra-violet light, oxidation, temperature fluctuations, and resistance to chemicals such as gas and oil drippings [4].

The early 1960s saw plans for two Canadian major orthotropic bridges, the Port Mann Bridge in British Columbia and the MacKay Pier-Ile Vert Bridge in Montreal, and the above mentioned two USA bridges, Poplar Street Bridge and San Mateo/Hayward Bridge. The Poplar Bridge crossing the Mississippi River connected East St Louis, Illinois to St. Louis, Missouri. Along with plans and design of the two major orthotropic bridges in the USA, a nation-wide investigation into riding surfaces ensued. The American Iron \& Steel Institute, New York City, commissioned research while the state transportation departments of California, Illinois, and Missouri built small steel deck bridges specifically for evaluating riding surface material for the two major bridges in the works [5].

The original Poplar Street Bridge riding surface called for a zinc rich paint coat followed by thin layers of coal tar epoxy and grit. An up to $11 / 2^{\prime \prime}$ leveling bituminous concrete containing latex and a $1^{\prime \prime}$ surface coat of the same completed the riding surface [6]. This riding surface was replaced in 1983. After 1983 the riding surface was replaced several times. To greatly stiffen the structure and provide for a composite action, the current replacement is a steel fiber reinforced lightweight Portland cement concrete with shear keys attached to the deck. The material used in the two riding surfaces prior to the current 
replacement consisted of a polymer slurry whose average life cycle was less than 10 years.

For the original San Mateo/Hayward Bridge deck riding surface, EAC was chosen. The material was durable enough to withstand traffic wear, differential bridge movements, and environmental stresses without cracking, oxidizing, or de-bonding and requiring only limited maintenance for nearly 35 years [4]. After 2002 more and more maintenance was required, as cracking was observed and in some places the EAC was shoving indicating it lost bond. The potential for steel deck corrosion increased. This was the case with pitting of the Coronado Bridge orthotropic deck in San Diego where the EAC riding surface was placed in 1969. Cracks were observed in the EAC in 1979, and de-bonding was detected by 1986 . The Coronado EAC riding surface was replaced with EAC in 1993 and is currently (24 years later) still performing well. The 1967 EAC of the San Mateo/Hayward Bridge was replaced with a Polyester Concrete in 2015, after being in service for almost 48 years.

\section{Epoxy asphalt concrete}

EAC is a sole source material consisting of epoxy resin and asphalt concrete mixed at high temperatures. Typical material property requirements are shown in the SAS project specifications in Table 1. Material properties were determined prior to the application on the San Mateo/Hayward Bridge through laboratory testing and field performance [7].

The epoxy mixed into the asphalt binder is a thermosetting material and once cured the binder remains stiffer at higher temperatures as compared with that of conventional asphalt. Additionally for the same reason, epoxy asphalt does not become brittle at cold temperatures. Asphalt paving equipment are used to install EAC in the same manner as the installation of conventional asphalt concrete.

In 1981, Caltrans conducted static and dynamic tests on epoxy asphalt concrete. The testing was conducted on composite beams consisting of a $4^{\prime \prime} \times 15^{\prime \prime} \times 7 / 16^{\prime \prime}$ steel base plate with a $2^{\prime \prime}$ thick epoxy asphalt wearing surface. The results showed the modulus of elasticity of the epoxy asphalt to range between $50 \mathrm{ksi}$ and $75 \mathrm{ksi}$ for the static tests and $50 \mathrm{ksi}$ to $92 \mathrm{ksi}$ for the dynamic tests, respectively [8]. Of note is a Caltrans sponsored testing of EAC composite beams in 2011/2012 that resulted in similar values, thus demonstrating consistent properties throughout the decades [9].

The history of EAC in California goes back to the early 1960s. Since then a number of notable successful EAC projects have been placed. In 1976 and 1977, the entire SFOBB concrete riding surface was overlaid with EAC which covered both the east and west spans. In service for some 28 years, the decking of the iconic suspension bridge west spans was repaved in 2005 with polyester concrete. The decking of the east spans' cantilever trusses was left in place without repaving, and only received stop-gap maintenance until 2013 when the new east spans of SFOBB was opened to traffic and demolition began on the old east spans.

Key components for the success of EAC projects include: a) adherence to required temperature parameters, b) proper compaction techniques and c) meeting tight time constraints of the specifications. The important elements are maintaining temperature control of the epoxy asphalt concrete at the batch plant, maintaining dwell time before discharging, and completing roller compaction of the epoxy asphalt concrete before the epoxy asphalt on the deck has cooled too much.

The cure rate of the epoxy binder varies with storage temperature of the binder components, mixing temperature and loading temperature. There are strict limitations for time between batching at the plant and placement on the bridge deck. Per the SFOBB east spans replacement specification special provisions for the SAS [10]: “The Contractor's attention is directed to the inter-relationship of batch temperature, hauling times and placement temperature for epoxy asphalt concrete specified in these special provisions."

The construction specifications of EAC require the binder components to be stored separately at the plant

Table 1

Properties of fully cured EAC

\begin{tabular}{lcc}
\hline Property & Value & Test Method \\
\hline Marshall Stability at $60^{\circ} \mathrm{C}, \mathrm{KN}$ (Minimum) & 40.0 & ASTM D1559-91 \\
Flow Value at $60^{\circ} \mathrm{C}, \mathrm{mm}$ (Minimum) & 2.0 & ASTM D1559-91 \\
Recovery at $60^{\circ} \mathrm{C}$, percent (Minimum) & 60 & ASTM D1559-91 \\
Air Voids in Total Mix, percent (Maximum) & 3.0 & ASTM D303/1188 \\
\hline
\end{tabular}


at different temperatures, proportioned $85 \%$ of a conventional asphalt binder with epoxy hardeners and 15\% epoxy resin binder. The epoxy-asphalt binder is then injected into the pug mill of the hot plant to be mixed with the dried aggregate at the mix design proportions.

The epoxy asphalt components which include the epoxy resin and the asphalt/curing agent are heated to $180-200^{\circ} \mathrm{F}$ and $300-310^{\circ} \mathrm{F}$ prior to mixing, respectively. The aggregate temperature is controlled to be in the range $235-255^{\circ} \mathrm{F}$. The mixed batch as it leaves the pug mill is controlled to be between 230 and $250^{\circ}$ F. The specifications state that, "Both epoxy asphalt binder and bond coat require a very rigid control of mixture, time and temperature."

A typical cure rate-temperature relationship specification is shown in Table 2. The table shows that the temperature of all batches in a truck load influence the time limits for transporting, placing and compacting EAC which creates a relatively complex operation. For example, if the average temperature is $230^{\circ} \mathrm{F}$ for EAC in a transport dump truck, the truck's concrete cannot be discharged until 69 minutes elapsed from time of first loading the truck, and, must be discharged before 94 minutes elapsed. These time limits create extra logistical operations that must be addressed. In other words, if the time of discharge exceeds $94 \mathrm{~min}$ utes, or drops below 69 minutes, the product curing and compaction can be negatively impacted.

EAC is also susceptible to ambient conditions during placement. The specification requirements state that paving shall not be done when air or deck temperatures fall below $50^{\circ} \mathrm{F}$. Temperature control is critical to achieving field compaction. To ensure a long fatigue life, the required maximum air void content after compaction must be $3.0 \%$, and to achieve this, compaction has to be completed before the EAC mat cools. Also, compacting a cold mat creates hairline micro cracks which cause premature failure of the riding surface.

The SFOBB specifications of EAC required the breakdown compaction for the EAC surface course to be performed with three coverages using steel-tired tandem rollers, completed before the temperature of the mix dropped below $180^{\circ} \mathrm{F}$. This was followed by three coverages of pneumatic-tired rollers. The final compaction was to be performed by at least three coverages using steel-tired rollers and to be completed before the mix dropped below $150^{\circ} \mathrm{F}$. Since thin lifts of EAC on steel decks tend to cool at a fast rate, the coordination between the time of loading the trucks at the plant and the time of unloading them in the field is very important. The speed of the paver is limited by the ability of the rollers to achieve the required number of coverages to achieve the specified density. If density is not achieved, the paver has to slow down. If the paver does not slowdown, the mat cools, and achieving the required density becomes more difficult if not potentially unlikely. The significance of these issues creates stricter logistical procedures to be followed because paver speed is governed from both ends: a) from the rear by the roller train, and b) from the front by the dump trucks that have a narrow time window within which to be unloaded. Therefore, the decision of when to load the trucks at the plant is particularly sensitive.

EAC was utilized recently on the SAS orthotropic decks of the SFOBB and the Fremont Bridge in Portland, Oregon. Although EAC is presumed to be constructed successfully on these two bridges, these projects demonstrated again the critical nature of the product application techniques. Hicks and Hicks documented some of the construction issues encountered during the placement of EAC on the Fremont Bridge which were related to logistic issues and time constraints [11].

As common during most any construction project, the SAS's riding surface application saw a few unanticipated problems that were solved. Lift height restrictions complicated placement where the SAS transitioned into the concrete structures on either side of the SAS steel structure. Another issue was that friction tests on the surface showed skid resistance was less than desirable for a new deck. This was rectified by abrasive blasting the surface with a selfpropelled steel shot blaster. Still another issue was time constraints required by contract was affecting the production rate. To ease production constraints, the minimum time before discharging was relaxed. To address the effect this had on proper cure of the riding surface, the time before opening the riding surface to heavy truck traffic was extended from 48 hours to at

Table 2

Time limits for transporting EAC for average mix temperatures of all batches in a truck load

\begin{tabular}{lcccccccccccc}
\hline Temp. $\left({ }^{\circ} \mathrm{F}\right)$ & 230 & 232 & 234 & 235 & 237 & 239 & 241 & 243 & 244 & 246 & 248 & 250 \\
Maximum (minutes) & 94 & 90 & 86 & 82 & 79 & 76 & 73 & 70 & 66 & 63 & 60 & 57 \\
Minimum (minutes) & 69 & 66 & 63 & 60 & 58 & 55 & 53 & 51 & 49 & 48 & 46 & 45 \\
\hline
\end{tabular}


least 7 days. This extended delay caused by the additional cure time and shot blasting operation to obtain the desired skid resistance did not affect the scheduled opening because EAC paving was not on the critical path of the overall project. However, for the San Mateo/Hayward Bridge EAC would have been on the critical path making such a change much more significant.

For the San Mateo/Hayward Bridge there was a concern about the sensitivity of EAC to application techniques in the planned accelerated bridge construction environment. It has been demonstrated that where there was breakdown of proper construction technique, there was premature distress in the riding surface. For example, the riding surface over the orthotropic steel deck of the Maritime Off-Ramp Bridge (a curved "horseshoe" crossing over Interstate 80 in Oakland, California) experienced cracking and other signs of distress shortly after opening in 1997. The horseshoe project distress was attributed to construction problems. Another example project was the EAC riding surface on the San Diego Coronado Orthotropic Bridge which was placed in 1969 and began to crack in 1979. That project was repaved in 1993, and it is still functioning well 24 years later. These examples and other examples where construction control techniques broke down, which resulted in pre-mature distress of the deck, was the motivation to investigate an alternative material that might be better adapted to an accelerated bridge construction project. However, since EAC has been shown to provide an excellent and long-life riding surface when designed and constructed properly, substantial considerations were still given to the use of EAC on the San Mateo/Hayward Bridge, and EAC was used as the laboratory and field performance baseline to evaluate the alternative material.

\section{Premixed polyester concrete}

Premixed-polyester concrete overlays have been used successfully in many parts of the USA and Canada. The first such overlays were placed in freeze/thaw and high chloride environments. Laboratory testing indicated low permeability by rapid chloride ion tests which were sometimes below 10 Coulombs [12]; and the overlay acting as a composite with the existing deck exhibited a lack of cracking beyond any working cracks already in the deck or new stress cracks as part of the whole deck. Also insitu testing on these early bridges by copper-copper sulfate $(\mathrm{Cu}-\mathrm{CuSO} 4)$ half-cell indicated an arresting of corrosion activity in reinforcing steel when compared to results prior to the overlay.

Polyester concrete consists of a polymer resin and aggregate at predetermined proportions, and thoroughly mixed together to form a workable polymer concrete [12]. It is consolidated into place by vibrating strike-off and finished to a desired texture similarly as done for a Portland cement concrete. This should not be confused with a multilayer polyester overlay where resin is flooded onto the deck and rock or chip is broadcast onto it. Two to three lifts are applied in this manner thus a "multilayer" is typically between $1 / 2^{\prime \prime}$ and $3 / 4^{\prime \prime}$ thick while it would be very difficult to place it any thicker. Multilayer systems have not had the longevity of premixed polyester concrete. Nor can they correct a profile, whereas premixed systems have been placed, sometimes, in thick sections such as 5 " or more to correct profile grade. Life expectancy of a multilayer system is 5-7 years though occasionally they have lasted more than 10 years. Life expectancy for a premixed polyester concrete system is 25 years and some first placements are now approaching 34 years.

The current specifications used for premixed polyester concrete are substantially the result of a 10 year Caltrans research endeavor beginning in 1973 to produce a viable thin overlay for concrete bridge decks. The first two projects were the nominal $1^{\prime \prime}$ thick polyester overlays on the Beaver Creek Bridge and Thompson Creek Bridge, both on Route 96 in Siskiyou County near the Oregon border. These were placed in 1983. These polyester decks are still rated to be in excellent condition, though this highway is lightly traveled. Other polyester overlays such as the polyester overlays placed in $1991 \& 1992$ on the heavily traveled I- 80 El Cerrito Overhead and the Gilman Undercrossing in Berkeley are still showing no signs of wear. These examples are relatively short bridges in which a lane was relatively easy to complete during a nighttime work window. The Marina Viaduct located in the Marina District of San Francisco, which is the approach and departure structure for the Golden Gate Bridge, was the first large bridge to receive a polyester overlay applied exclusively between the hours of $10 \mathrm{PM}$ and $5 \mathrm{AM}$. A mobile mixer and self- propelled paver were required. The bridge was approximately 250,000 square feet. The overlay was completed in 1992. When the bridge was replaced in 2012, the overlay was still showing little, if any signs of wear. Just prior to its replacement, skid resistance measures were taken across the entire bridge. 
Of interest to some was the skid resistance values measured in 2010 were comparable to those measured during construction in 1991/92. A significant observation was the spalled concrete in the walkway caused by corroding high steel. The walkway did not receive the overlay. The travel way had a lot of high steel, some of it was exposed by traffic prior to placement of the overlay. Thus the effectiveness of the polyester concrete in preventing corrosion is clearly demonstrated. One of the objectives of a polyester overlay is to protect deck steel.

Another property of polyester concrete is its adaptability to be placed throughout a significant range of ambient temperatures. Being a free radical system, set times can be controlled by initiators and accelerators that are added in very small percentages of the resin to accommodate changes in temperature. For example, during the same period polyester concrete on the Marina Viaduct was being opened to traffic in as little as 2 hours after placement, which was sometimes when temperatures dropped to $45^{\circ} \mathrm{F}$, approximately 150,000 square feet of bridge deck was placed on bridges on I -15 near Victorville in Southern California's high desert with ambient temperatures as high as $100^{\circ} \mathrm{F}$. Placement over a large temperature range was considered an attribute for the San Mateo/Hayward Bridge riding surface replacement. Since its placement was anticipated to be conducted around the low and high temperatures of a given weekend, controlling the resin set times over a potential range of ambient temperatures was essential.

Design life expected to be at least 25 years, it is a rarity when a polyester concrete needs replacement before 20 years. Much has been learned since the Beaver and Thompson Creek overlays regarding durability, such as a deficiency in resin content and/or thicknesses less than 3/4 inch tended to result in shorter life. Also a hard lesson learned was that a too efficient aggregate grading which results in a reduced resin demand (not to be confused with related resin content) can increase the modulus of elasticity of polyester concrete. Too high a modulus of elasticity can cause the stress capacity to be less than the stress demand. Because of this, the grading must be adjusted to ensure a minimum resin demand. To achieve this, many states now limit the modulus of elasticity by specification, while Caltrans places restrictions on the aggregate gradation requirements.

Polyester overlays are widely used throughout California. Polyester concrete was used extensively on the concrete structures of the new east spans of the SFOBB to accommodate profile grade between the several structures comprising the new east spans. The entire 1.3 mile long Skyway portion of the new east spans, which is east of SAS, has a polyester overlay to provide the smooth riding surface and to protect the interface of the precast box girder segments. The Richmond/San Rafael Bridge and the entire west spans of the SFOBB had polyester overlays placed in 2005-06 under tight nighttime working windows. The overlays on these two heavily traveled major bridges in the Bay Area are preforming admirably. It is nearly impossible to drive any distance on a California highway without coming across a bridge that has a polyester overlay. Those in urban areas are almost always done at night under strict lane closure time periods.

\section{Evaluating polyester concrete on steel decks}

With the decision to proceed with investigating the possibility of using a polyester pre-mixed concrete on an orthotropic steel deck, preliminary investigations ensued. The very first inquiry was the prime coat for the polyester concrete. On concrete bridge decks a prime coat of methacrylate resin is flooded onto the concrete substrate prior to placement of polyester concrete. The prime coat's purpose is to wet out the concrete surface providing intimate contact between the overlay system and the concrete deck, to enhance the surface strength of the concrete as the low viscosity resin penetrates any small defects or cracks, and to act as barrier between alkali concrete and the isophthalic polyester resin. The only purpose of a prime coat on the steel surface would be to provide for intimate surface contact to enhance bond. Given enhancing surface contact was desirable, the possibility of adding zinc in the same general manner as zinc is added to a paint to provide galvanic protection was pursued. A zinc rich paint meeting Caltrans specifications was compared to prime coat resin in which zinc meeting the requirements for the paint was added to the resin at the same rate as added to paint. Steel samples were painted with the zinc rich paint and zinc rich prime coat resin. Resistance to corrosion was similar for both materials as observed from exposing the specimens to salt spray, and the zinc had no ill effect on the prime coat including its bond to steel. Here the prime coat could serve the same function as a zinc rich paint thus eliminating a time consuming step without loss of performance. 
Small scale field evaluations were done. These provided for evaluating steel preparation requirements, resin alternatives for the zinc rich prime coat, spread rate for various prime coat resins, techniques for applying the prime coat, and even specification language. They also provided a place for Contractors to develop skills for placing the prime coat. Dodge Point Viaduct in Southern California served as a field test on a lightly traveled highway in Mono County. This bridge is less than 70 feet long, and has a corrugated steel deck whose asphalt riding surface was in need of replacement. Construction was per a competitive bid providing information for estimating cost. Another field test evaluation was a $200^{\prime}$ by $10^{\prime}$ strip placed on the San Mateo/Hayward Bridge done by contract change order during a weekend long repair on another part of the 7 mile long bridge. Also Missouri Department of Transportation (MoDOT) was using polyester concrete with the zinc rich prime coat to repair relatively large areas of the Poplar Street Bridge which was losing large areas of its slurry seal riding surface to traffic stress. MoDOT reported very positively about the repairs. The polyester concrete was working better than the other repair materials they were using.

However, definitive laboratory testing was required to establish the possibility of polyester concrete being a reasonable alternative to EAC on the San Mateo/Hayward orthotropic deck. During the same time as the field trials, Caltrans initiated a comprehensive research project with the University of Missouri, in Columbia. It was felt only such a comprehensive research project could determine if polyester concrete could be a reasonable alternative to EAC. The Principal Investigator for the research project at the University of Missouri was Professor Vellore S. Gopalaratnam [9].

\section{Laboratory evaluation}

The repetitive deflections orthotropic bridge decks experience from heavy truck wheel loads cause potentially large fatigue tensile strains in the riding surface, shear stresses on the bond line of the surfacing to the steel deck plate, and smaller induced fatigue stresses in the steel deck components. A characteristic of orthotropic decks is that truck wheel loading deforms the steel deck plate with relatively large deflections. The strain levels measured at the top of an orthotropic steel bridge can be in the order of $1400 \mu \mathrm{m} / \mathrm{m}$ compared with estimated strains levels of $120-150 \mu \mathrm{m} / \mathrm{m}$ encountered in normal pavements [13].

The large deflections also can result in high strains and shear forces at the interface of the riding surface. Deflection across the lateral directions can be particularly critical as the steel deck plate deflects between the longitudinal ribs by wheel contact on either side of the rib. It was important to know how a wellbonded polyester concrete would behave under these conditions. It was important to know if the polyester concrete modulus of elasticity was still low enough to ensure a higher shear stress capacity than the shear stress demand at the bond interface, and its resistance to stress cracking under expected loads.

With the replacement materials for the San Mateo/Hayward Bridge deck riding surface narrowed down to the original EAC that had performed so well, and a premixed polyester concrete, developed by Caltrans, that had also been performed well on concrete decks since 1983, the comparative laboratory research study at the University of Missouri began [9]. Several performance tests were conducted to compare polyester concrete and EAC which included:

- Flexural fatigue performance at $32^{\circ} \mathrm{F}, 70^{\circ} \mathrm{F}$, and $120^{\circ} \mathrm{F}$ up to 10 million cycles.

- The static and fatigue stiffness contributions of the two wearing surface systems to the steel

- deck plate at the three test temperatures.

- The load rate sensitivity at different fatigue test frequencies of $1 \mathrm{~Hz}, 2.5 \mathrm{~Hz}, 5 \mathrm{~Hz}, 7.5 \mathrm{~Hz}$,

- $10 \mathrm{~Hz}, 15 \mathrm{~Hz}$ and at a quasi-static rate

- The ultimate static load tests

- Evaluation of any crack initiated prior to 10 million cycles at the three temperatures.

The test sample design and loading were idealized to the San Mateo/Hayward Bridge deck. Composite $4^{\prime \prime} \times 18^{\prime \prime}$ test samples consisted of $5 / 8^{\prime \prime}$ thick steel plate and $2^{\prime \prime}$ thick riding surface material. Fatigue test loading was determined based on AASHTO T 14 provisions for design loads for orthotropic decks including the multiple presence factor and impact factor for local analysis. The ribs were idealized to be non-yielding simple supports and tire loads assumed to be directly on the steel. Both of these analytical conditions made for an even more conservative analysis of the actual field stresses on the bridge.

The research results indicated that polyester concrete would provide similar performance as EAC. It also revealed that polyester concrete was stiffer than EAC at typical temperatures for the San Mateo/Hayward Bridge. This finding was considered 


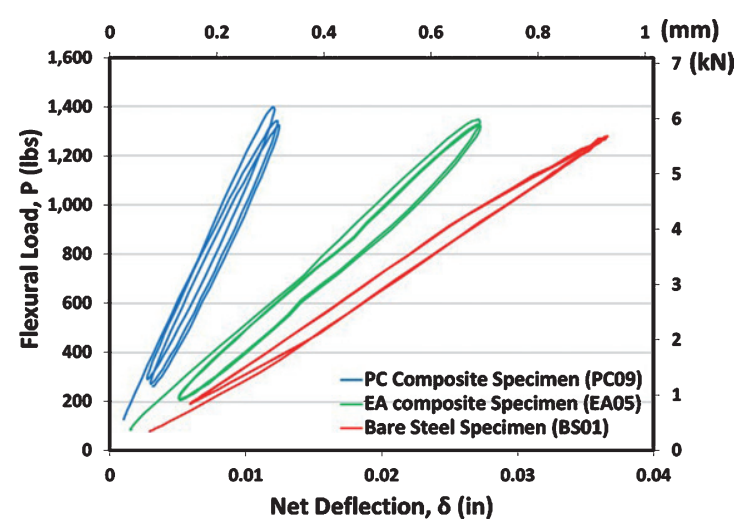

Fig. 4. Typical static load-deflection responses for bare steel and composite specimens at room temperature [9].

an advantage of the polyester concrete. With a higher modulus of elasticity, polyester concrete adds more structural integrity. Being 12\%-15\% lighter than EAC, polyester concrete reduces the dead weight which was also an advantage. However, these two advantages were not considered decisive factors. Figure 4 shows hysteresis of a typical static flexural load versus net deflection for composite specimens consisting of polyester concrete and EAC over steel as well as for only bare steel [9].

\section{Accelerated bridge onstruction}

The decisive factor of polyester concrete was the well-established construction practices within a tight time constraint which historically showed a reduced risk of compromising the material during installation when compared to EAC. EAC adherence to temperature and time restrictions governing batching and placement are critical to EAC performance. These restrictions are sensitive to ambient temperatures. Even polymerization of the epoxy component is related to time/temperature during installation. With EAC being centrally batched and delivered by large trucks, once batched into a truck, there is little flexibility in timing for proper placement. At any given time, multiple truckloads of EAC are on hand. This means that any unexpected stop in the paving operations, or even just a change in the rate of paving can potentially make meeting the time and temperature requirements problematic. An unanticipated halt of the paver may result in a substantial amount of material being compromised. Since EAC is batched off site at stationary asphalt batch plant, restarting after an unexpected stop of discharge must consider the possibility of creating even more tons of potentially compromised material. Also, a surface treatment operation is needed to provide friction [14].

Polyester concrete, in contrast, is batched and mixed by a mobile continuous mixer. The mixed polymer concrete is immediately discharged into a moving paver's hopper. The batching rate is instantaneously proportioned to the paving rate. Even a long delay from an unexpected stop of the paving operation is a non-issue for quality since there is no more than the small amount of material in the hopper needing attention at any given time. Control of the added initiator system and accelerators allow for regulating working time and strength gain under very diverse temperature ranges. Such control expedites a traffic-ready surface in as little as 1.5 hours during ambient temperatures ranging from $45-100^{\circ} \mathrm{F}$. Quick set time also facilitated construction traffic as work progressed. The zinc rich prime coat adds another layer of corrosion protection. The surface is textured to obtain skid properties by cement masons during placement. As shown on the Marina Viaduct the friction value can last for decades.

\section{Replacement of the $\mathbf{1 9 6 7}$ riding surface}

Plans and Specifications for removing the 1967 EAC riding surface and replacing with a premixed polyester concrete having a zinc rich prime coat were produced and published for competitive bid [15]. The successful bidder was a joint venture and the contract was awarded. The Contract provided for the bridge to be completely closed to the public over 3 weekends, 55 consecutive hours for each weekend [15]. However, the Contractor only needed two weekends with neither weekend needing the entire 55 hours.

The Contractor began practicing and honing in on techniques early April 2015. This was done within night time closures. During the first night time the Contractor did about 100 lane feet. The last practice done on May 1 accomplished 350 lane feet. Also the quality went up. About 800 lane-feet was completed during these night time shifts. Special care was needed to remove the EAC over the splice plates so as not to damage them. This required a fair amount of handwork. That first night left the splice plates scarred a bit. It became apparent of the benefits of doing as much as this hand work as possible before full scale production during weekend shutdown of the bridge. The EAC over the longitudinal splice plates were removed and replaced during the week at night 


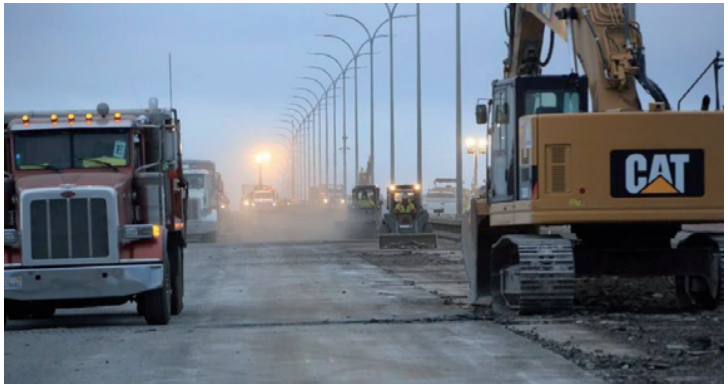

Fig. 5. Removal process of EAC (Courtesy of John Huseby, Caltrans)

with a $2^{\prime}$ wide strip polyester concrete. These longitudinal strips were simply placed within the old EAC riding surface. The $2^{\prime}$ wide strips then served as a screed to control the profile grade when the full scale weekend work began. The edge of deck profile grade was controlled using the barrier rail while the center line profile grade was controlled by the center rail's concrete base. There are two longitudinal splice plates between the edges of deck and the center barrier rail. These splice plates run the entire length of the orthotropic bridge. The transverse splice plates were removed during the weekend work but well ahead of the heavy equipment removing the EAC.

On Friday, May 8, 2015 at 10 PM the entire bridge was closed. Tractor trailer dump trucks were lined on both sides of the high-rise portion of the bridge, and moved in when a lane was taken at $8 \mathrm{PM}$ just prior to full closure. The noise of pavement-breakers, excavators, loaders, and a variety of other heavy and hand equipment denoted the removal of 11 million lbs. of the 48 year old EAC (Fig. 5).

One contracting company making up the joint venture did the east bound direction while the other did the west bound. Loaded volumetric batched mixing trucks rolled onto the east bound lanes deck discharging polyester concrete into the pavers after midnight when removal and preparation of the deck made ready enough deck to be paved (Fig. 6). The west bound lanes allowed for a few more hours of deck removal before commencing with paving.

For preparation of the deck to receive the polymer concrete, the deck was abrasively cleaned by selfpropelled shot blasters followed by hand-held "sand" blasting until it met contract compliance with SSPCSP 6/NACE. A liberal coat of methacrylate resin containing zinc powder was then applied to the surface. The process of removal, preparation and paving continued on day and night through the weekend with

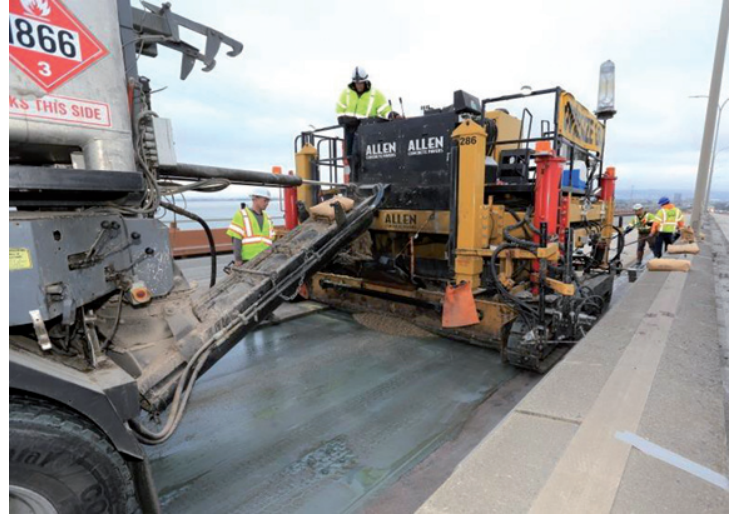

Fig. 6. A continuous volumetric mixing/batching truck discharging polyester concrete into the paver (Courtesy of John Huseby, Caltrans).

the last of the paving completed at $1 \mathrm{AM}$ on May 11 . Around 3.5 lane miles of the bridge was resurfaced when the bridge was opened prior to the Monday morning scheduled 5 AM deadline.

The work done on that the first weekend was evaluated and discussions took place between Caltrans and the Contractor. One lesson a Contractor learned from the 1st weekend work was that deck preparation became part of the critical path stalling the paving rate on a portion of the bridge. Some of this portion was rejected and later removed and replaced by the Contactor during several nighttime closures in June and July. As a side note this demonstrated the overlay met an objective of being repairable.

Completing the replacement work commenced on Memorial Day weekend, the bridge being closed from Friday May 22 @ 10PM until Monday May 25 @ 3 AM. An additional shot blaster was added to the production train and the paver catching up to the preparation operations was no longer an actuality. Paving was completed Sunday while the rest of the work shift was used for expansion-joint work, barrier rail maintenance work, striping, cleanup, and other miscellaneous items on other portions of the bridge including at the toll booth complex.

Eleven mobile volumetric mixers \& four pavers modified specifically to place polyester concrete were on hand. Twenty-six tanker trailers each containing 40,000 lbs of polyester resin meeting all contract compliance tests were delivered. Approximately 3,000 cubic yards of polyester concrete was placed. An estimated 64,000 lbs. of zinc for galvanic protection are on the deck as part of the prime coat. Pull off testing indicated nearly 900 psi on $2^{\prime \prime}$ 
diameter cores and surface friction values were well above the required 0.35 thus meeting the skid resistance objective [16].

Following the Memorial Day weekend work, Caltrans continued inspecting \& evaluating for contract compliance and general quality. During night time and non-peak time day closures, the entire 420,000 square feet of deck was profilegraphed to measure smoothness for ride quality and also "chain dragged" to detect any anomalies (less than $1 / 2 \%$ of the deck area delaminated in discrete area where preparation did not stay ahead of paving.) Delaminated area was removed and replaced as appropriate while grinding the deck was done to meet ride smoothness requirements.

The replacement of the San Mateo/Hayward EAC riding surface, an Accelerated Bridge Construction project, was successfully completed without compromise. The polyester concrete replacement is estimated to be faster by a factor of 2.75 (36\% of the time) then EAC. This is based on production rate of the bulk of the EAC placed on the Fremont Bridge where most of the 140,000 square feet of old EAC was removed and replaced in 2 weekends in 2011 compared to production rate of the bulk of the polyester concrete placed on the San Mateo Bridge where most of the 420,000 square feet of old EAC was removed and replaced in 2 weekends in 2015.

\section{Summary}

Polyester concrete was used for the first time on an entire major orthotropic deck on the San Mateo/Hayward Bridge. For the second time the riding surface material used on the orthotropic portion of the San Mateo/Hayward Bridge gained national attention.

There are discussions of the merits EAC as a riding surface for orthotropic decks in the 2012 version of the FHWA Manual on Design of Orthotropic Bridges. There are now considerations to include discussions on the merits of premixed polyester concrete as a riding surface for orthotropic decks in a later version of the FHWA Manual on Design of Orthotropic Bridges. If this surface performs as well as the initial San Mateo/Hayward Bridge deck surface material as the laboratory results suggest, a replacement of the San Mateo/Hayward surface would not be constructed until after centennial celebrations of the Eisenhower Interstate Highway System. And just like the original EAC riding surface of San Mateo/Hayward Bridge,
Chinese and Canadian engineers are showing an interest in polyester concrete for their orthotropic decks.

\section{Conclusions}

An accelerated bridge construction project was completed using a polyester concrete riding surface that replaced the aged EAC riding surface without compromise. The actual removal of existing EAC and replacement with polyester concrete was $36 \%$ of the estimated time of replacing with EAC if no trucks were turned back due to any construction issue. This amounted to a significant reduction in significant user costs of the polyester concrete as compared to EAC.

The University of Missouri research study indicated that polyester concrete would provide similar performance as EAC. It also showed that polyester concrete, being stiffer than EAC at typical temperatures for the San Mateo/Hayward Bridge, added more structural integrity. Additionally, polyester concrete is $12-15 \%$ lighter thus reducing dead weight but these two advantages were considered minor benefits.

Both polyester concrete and EAC are quality riding surfaces for orthotropic bridge decks. EAC was used on the SFOBB's signature structure SAS deck in 2013 instead of polyester concrete. Since other bridge elements of SFOBB were still under construction the riding surface was not on the critical path so there was less risk since trucks could be turned back or production rates altered or cure time increased without adding user costs.

The decisive advantage of polyester concrete was the well-established construction practices within a tight time constraint which historically showed a reduced risk of compromising the material during installation. On the other hand EAC adherence to temperature and time restrictions governing batching and placement are critical to its performance. These restrictions added risk to compromising the material during the accelerated bridge construction project.

\section{References}

[1] Mangus A, Shawn S. Orthotropic Deck Bridges. Bridge Engineering Handbook. Chapter 14, edited by Chen, WaiFah and Duan, Lian. CRC Press LLC. Boca Raton. Florida, 2000.

[2] Balala B. Results of Studies of Materials of Orthotropic Deck Pavement: San Mateo-Hayward Bridge. Caltrans Internal Report. Division of Bay Toll Crossing. Department of Public Works, California, 1966. 
[3] Gilligan J. Wearing Surfaces for Orthotropic Decks. AISC Engineering Journal. 1964:50.

[4] Seim C, Ingham T. Influence of Wearing Surfacing on Performance of Orthotropic Steel Plate Decks. Transportation Research Record: Journal of the Transportation Research Board, No. 1892, TRB, National Research Council, Washington, D.C., 2004, PP. 98-106.

[5] Seim C. Practical Considerations in Design of Orthotropic Decks. ASCE National Structural Engineering Convention. April 14-18, 1975.

[6] Keller K. Day by Day. Missouri Highway News. Special Issue in January-February. Published by Missouri State Highway Commission, 1968, PP. 15-25.

[7] Balala B. First Orthotropic Bridge Deck Paved with Epoxy Asphalt. Civil Engineering, American Society of Civil Engineering, 1968.

[8] Caltrans. Golden Gate Bridge Deck. Memo from Caltrans Office of Transportation Laboratory to M.E. Harding, Acting Director of Caltrans District 4, 1981.

[9] Gopalaratnam V. Evaluation of Wearing Surface Systems for the Orthotropic Steel Deck of the San Mateo Hayward Bridge. Report prepared for the California Department of Transportation. December 2012. (Project 59A0742), 2012.
[10] Caltrans. Project Special Provisions. Contract No. 0401220F4, 04-SF-80-13.2/13.9. August 1, 2005.

[11] Hicks C, Hicks G. Epoxy Asphalt Concrete (EAC) Used to Repave the Fremont Bridge in Portland Oregon, 2012. Http://ine.uaf.edu/autc/files/2012/03/Hicks-Fremont -Bridge-Project-Write-Up-3-18-12-final-A-4.pdf

[12] Maggenti R. Polyester Concrete in Bridge Deck Overlays Report. SFOBB East Spans Safety Project Skyway Structure. O4-ALA/SF-80, 2001.

[13] Medani T. Asphalt Surfacing Applied to Orthotropic Steel Bridge Decks - Literature Review. In commission of the Dutch Ministry of Transport, Public Works and Water Management (Contract No. 97-009991/PIHA d.d. 03-12-1999). Report 7-01-127-1. ISSN 0169-9288, 2001, P. 69.

[14] Gaul R. Epoxy asphalt concrete - a polymer concrete with 25 years' experience. ACI Special Publication. 1996;166:233-52.

[15] Caltrans. Project Special Provisions. Contract No. 04041004, 04-SM,Ala-92- R14.4/R18.8,R0.0/R2.6. June 30, 2014.

[16] Maggenti R, Brown K. Accelerated Bridge Construction to Rehabilitate Aging Highway Structures. Structure Magazine, Bridges. A Joint Publication of NCSEA/CASE/SEI. October 2015, PP. 18-21. 